\author{
Executive Function and Academic Achievement: Longitudinal Relations \\ from Early Childhood to Adolescence \\ Sammy F. Ahmed \\ Sandra Tang \\ Nicholas E. Waters \\ Pamela Davis-Kean \\ University of Michigan
}

Corresponding Author:

Sammy F. Ahmed

Department of Psychology

University of Michigan

sammyfa@umich.edu 


\begin{abstract}
Data from the NICHD Study of Early Child Care $(N=1273)$ were analyzed to assess the longitudinal relations among executive function (EF) components in early childhood (54 months) and adolescence (15 years) and their prediction of academic achievement. We found that after controlling for early achievement, demographic and home environment variables, only working memory at 54 months significantly predicted working memory at 15 years and that working memory was the only significant EF predictor of achievement at age 15 . In contrast, all early achievement measures were significant predictors of later achievement. Further, no demographic or home environment variables at 54 months significantly predicted $\mathrm{EF}$ at 15 , and only maternal education significantly explained variance in adolescent math and literacy achievement. These findings demonstrate the predictability of working memory and highlight its importance for academic outcomes across development. However, the lack of associations of preschool inhibition and attention measures, after controlling for early achievement, demographic and home environment variables, to corresponding measures in adolescence suggests the need for more developmentally sensitive measures of EF. Given that the EF measures used in this study are commonly used in educational and psychological research, more care should go into understanding the psychometric properties across development.
\end{abstract}

\title{
Keywords
}

Executive Function, Academic Achievement, Early Childhood, Adolescence 
Executive Function and Academic Achievement: Longitudinal Relations from Early Childhood to Adolescence

Executive function (EF) refers to a broad set of neurocognitive processes involved in purposeful, goal directed control of thought, behavior and emotion that allow for adaptation to fluctuating environmental demands (Shonkoff \& Phillips, 2000) and includes working memory, attention control, response inhibition and thoughtful planning of future actions (Zelazo, \& Carlson, 2012; Willoughby, Blair, Writh, \& Greenberg, 2010). A large body of research has demonstrated substantial relations between executive function skills and an array of developmental, academic, cognitive and behavioral outcomes; and have been linked to achievement, literacy, health, wealth, and criminality (Duncan et al., 2007; Lan et al., 2011; Moffitt et al., 2012). In recent years, interest has steadily mounted on understanding the early development of EF, mainly due to the relevance of these skills for children's school readiness and academic achievement.

Despite years of research charting the early growth of EF and their relations to emergent academic skills (Friso-van den Bos, G Van der Ven, Kroesbergen, \& Van Luit, 2014; Lee \& Bull, 2014), few studies have examined these relations across development to see if they predict to later EF skills or academic outcomes. Understanding longitudinal relations between executive functions and academic skills is important for several reasons. First, since aspects of EF show protracted maturation across development (Zelazo \& Carlson, 2012), it is unclear whether existing measures of EF tap into the same underlying construct across developmental stages. Very few studies examine developmental changes in EF using longitudinal data, and those that do, either focus on relatively short intervals of time (e.g., Hughes et al. 2010; Harms et al. 2014; Willoughby et al. 2012), use cross sectional data (e.g., Best, Miller, \& Naglieri, 2011; Shing, 
Lindenberger, Diamond, Lee, \& Davidson, 2010) or do not examine changes across major developmental periods (Boelema et al. 2014; Brydges, Fox, Reid, \& Anderson, 2014; Wiebe, Sheffield, \& Espy, 2012).

Second, although the nature, direction and strength of relations between EF and emerging academic skills are generally well understood in early childhood (e.g., Friso-van den Bos, van der Ven, Kroesbergen, \& van Luit, 2014; Fuhs \& Day, 2011; Yeniad, Malda, Mesman, van IJzendoorn, \& Pieper, 2013) and, to a lesser degree, during adolescence (e.g., Latzman, Elkovitch, Young, \& Clark, 2010; Luciana, Conklin, Hooper, \& Yarger, 2005; Samuels, Tournaki, Blackman, \& Zilinski, 2016), the specific associations between EF skills in early childhood and academic achievement in adolescence remain less clear. Testing whether specific associations among EF and academic skills vary across development could shed light onto specific developmental periods during which $\mathrm{EF}$ is more predictive of academic achievement.

Third, many studies that chart the growth of EF, and its impact on academic achievement, especially across a wide developmental span of years, have not carefully considered the role of demographic and family-level variables in their longitudinal models. Given the importance of demographic (SES, gender, etc.) and home (parental involvement, cognitive stimulation, etc.) influences during early childhood, and their impact on cognitive and academic outcomes across development (Davis-Kean \& Sexton, 2009; Blair, 2010; Dearing, \& Tang, 2010; Hackman, Gallop, Evans, \& Farah, 2015; Sarsour et al., 2011), their inclusion in longitudinal examinations of $\mathrm{EF}$ and achievement is necessary. This will allow us to understand the degree of predictability of early EF and achievement measures while holding constant relevant covariates that can influence the interpretation of longitudinal associations. The inclusion of demographic and family-level covariates can also reveal insights about the relative contribution of early cognitive, 
academic, and contextual variables on later performance and achievement.

Hence, the present study examines relations between EF in early childhood (54 months) and adolescence (15 years) using a prospective longitudinal design in a large, national database (National Institute of Child Health and Human Development Study of Early Child Care). Testing longitudinal associations across two assessments will allow us to evaluate the long-term predictability of EF from early childhood through adolescence. Similarly, we will also test relations between EF measures in early childhood and academic achievement in adolescence in order to build on a substantial body of literature demonstrating cross-sectional and short-term associations between $\mathrm{EF}$ and academic achievement.

\section{The Development of Executive Function}

Although definitions vary, executive functions mainly refer to an individual's ability to complete tasks and purposefully guide their mental thoughts and behaviors to achieve certain goals (Cartwright, 2012). These abilities emerge at early infancy and continue to develop well into early adulthood and include working memory, sustained attention, and response inhibition (Blair, 2002; Zelazo, \& Carlson, 2012). Research has demonstrated three major cycles of EF development when there appears to be accelerated periods of growth in EF skills (18 months to 5 years; 5 to 10 years; and 10 to 14 years), which parallel models of neural and cortical development. By three years of age, children display varying levels of response inhibition, working memory, and the ability to shift attention (Hughes, 1998), which indicates that they can control their own behavior and attend to and remember information to complete tasks. Inhibitory control improves drastically between ages 3 and 6 (Montgomery \& Koeltzow, 2010), while attentional shifting and working memory improves between the ages of 4 and 5, and domain general cognitive control improving markedly between 7 and 9 years of age and continues to 
develop into adulthood (Jacques \& Zelazo, 2001; Smidts, Jacobs, \& Anderson, 2004).

From a developmental and educational perspective, the early cycles of EF development have been a focal point of research given its relevance for school readiness and early academic achievement. However, the development of EF components and their relations to academic achievement during the later stages of development is less understood. Further, predictability of early measures of $\mathrm{EF}$ to later measures of $\mathrm{EF}$ has not been examined across major developmental stages and it is unclear if this is a stable construct across time.

\section{Associations Among EF Measures Across Development}

There are limited studies that examine developmental changes in EF using longitudinal data. Studies in this area have either been constrained to a short age range, focus on a specific developmental stage (early/late childhood or adolescence, etc.), or have included a limited set of EF assessments. For example, several studies have reliably documented the growth of EF during early childhood (e.g., Hughes \& Ensor, 2011; Hughes et al., 2010; Wiebe, Sheffield, \& Espy, 2012). Willoughby, Wirth, and Blair (2012) found that EF tasks demonstrated strong measurement invariance from 3 to 5 years, and Fuhs and Day (2011) found EF tasks are invariant among preschool-aged children. These studies suggest that there is demonstrable growth in EF skills during early childhood, and also stability in EF assessments in young children.

Studies examining developmental changes during adolescence focus on relatively short intervals of time. Harms and colleagues (2014) found that both behavioral and electrophysiological measures of EF at age 8 were associated with similar measures at age 12, suggesting short-term stability of EF during the transition to early adolescence. Other researchers have employed similar techniques and arrived at similar conclusions. Boelema et al. (2014) 
found that the rank-order stability of EF components was preserved from age 11 to age 19 and that significant growth in these components transpires during this developmental period.

Conversely, Brydges, Fox, and Anderson (2014) showed that EF structure significantly differed from 8 to 10 years of age, suggesting differentiation of these skills during late childhood and into adolescence. Given that EF components undergo substantial reorganization over the transition from childhood into adolescence (Shing et al., 2010), it is important to examine the consistency and reliability of early EF across development. Furthermore, it is unclear whether commonly used EF measures are capturing similar constructs across development. Examining associations of children's EF across a wide age range can illuminate construct validity and measurement invariance over time.

\section{Executive Function and Academic Achievement}

Associations between EF skills and academic achievement have been extensively studied in various developmental stages and across multiple domains. Years of research has firmly established the contribution of young children's EF to emerging and persistent mathematics and literacy achievement (e.g., McClelland et al., 2007; Gathercole \& Pickering, 2000; Blair \& Razza, 2007; Lan, Legare, Ponitz, Li, \& Morrison, 2011). Complex EF skills that require the monitoring of overt, deliberate activities, are particularly useful in a learning environment where students are constantly expected to pay attention, follow rules and concentrate on various cognitive and behavioral tasks (Anderson, 2002; Blair, 2002; Blair \& Razza, 2007; Diamond \& Lee, 2011; Samuels, Tournaki, Blackman \& Zilinski, 2016).

Several recent studies reveal associations between children's EF skills and mathematics and literacy performance during early childhood (e.g., Willoughby et al., 2012; Miller \& Hinshaw, 2010, Blair \& Razza, 2007; Bull \& Scerif, 2001). This relation holds true for global 
measures of EF (e.g., Welsh, Nix, Blair, Bierman, \& Nelson, 2010; Adams, Bourke, \& Willis, 1999; Gathercole \& Pickering, 2000), separate components of EF (e.g., Lan, Legare, Ponitz, Li, \& Morrison, 2011), and persists across development (e.g., Blums, Belsky, Grimm, \& Chen, 2017; Bull, Espy, \& Wiebe, 2008; George \& Greenfield, 2005; Hitch, Towse, \& Hutton, 2001). For example, children's inhibition and working memory have been associated with math and reading achievement in kindergarten and first grade (Blair \& Razza, 2007; Espy, Bull, Kaiser, Martin, \& Banet, 2008) and aspects of attention control have been associated with math performance in young childhood (Bull \& Scerif, 2001; Duncan et al., 2007). Further evidence demonstrates relations among EF skills and achievement through late childhood and early adolescence (e.g., Stipek \& Valentino, 2015; van der Sluis, Jong \& van der Leij, 2007; Gathercole \& Pickering, 2000; St Clair-Thompson \& Gathercole, 2000; Altemeier, Jones, Abbot \& Berninger, 2006). However, many of these studies focus on relatively short intervals of time there are few studies that examine long-term associations among separate EF components in early childhood and math and reading achievement during adolescents, using prospective longitudinal designs.

\section{Demographic and Home Predictors of EF and Achievement}

Socioeconomic status (SES) is a multidimensional construct that includes various economic and social characteristics including income, occupation, and education. SES has long been linked to an array of developmental and health-related outcomes emerging as early as infancy and subsisting across the lifespan, from cognitive ability and academic achievement to physical and mental health (Adler \& Rehkopf, 2008; Bradley \& Corwyn, 2002; Conger \& Donnellan, 2007; Davis-Kean, 2005; Lawson, Hook, \& Farah, 2017; McLoyd, 1998; Sirin, 2005). Even prior to entering school, meaningful SES-related differences exist in language, 
cognitive, academic, and social skills, which likely put children on course for very different developmental trajectories (Morrison, Bachman \& Connor, 2005). Moreover, findings from the field of neuroimaging have revealed that SES disparities tend to be disproportionately associated with differences in the structure and function of the hippocampus, amygdala, and the prefrontal cortex (PFC), which are brain systems associated with executive processes (see Brito \& Noble, 2014; Hackman \& Farah, 2009).

Recently, researchers have begun to explore potential mechanisms underlying the association between socioeconomic disparities and variation in $\mathrm{EF}$ and academic performance including various aspects of parenting that may help buffer against, or in part explain, some of the potentially deleterious effects associated with socioeconomic disparities during sensitive periods of development (Farah, 2017; Fay-Stammbach, Hawes, \& Meredith, 2014; Geoffroy et al., 2010). Several studies examining the role of parenting and aspects of the home environment in promoting children's cognitive and academic growth demonstrate associations between factors such as parental expectations, maternal warmth/responsivity, family companionship and home enrichment activities, and children's EF skills and achievement prior to entering school (Bernier, Carlson, Deschênes, \& Matte-Gagné, 2012) and into elementary school (Davis-Kean, 2005;

Davis-Kean \& Sexton, 2009; Sarsour et al., 2011). Moreover, studies typically measure familylevel variables concurrently or in temporal proximity to the outcomes of interest (for exception, see Hackman, Gallop, Evans, \& Farah, 2015). Thus, these studies show that understanding both the SES context as well as the home context is important for understanding child outcomes such as EF and achievement. Many studies that have examined EF components and math and reading achievement, however, have not taken these important variables into consideration as important 
covariates when examining the association between early and later EF and achievement, especially across a wide range of years, spanning multiple developmental stages.

\section{Current Study}

Hence, the current study examines relations among EF components and academic achievement from early childhood to adolescence. Our central aims are to understand the longitudinal predictability of EF components across two important developmental periods, and their contribution to adolescent math and literacy skills. Testing these associations using separate indicators of EF and achievement will allow us to understand which aspects of EF are stable and predictive across time, their relative importance for later math and literacy achievement, and how specific aspects of the early home environment contribute to the development of these skills.

Thus, the present study proposes the following questions:

1) Controlling for important demographic and home-environment variables, what is the association between early executive function components (working memory, inhibition, and attention, at 54 months) and EF (working memory, inhibition, and planning) and academic achievement (mathematics and literacy) at age 15 ?

2) Controlling for important demographic and home-environment variables, what is the association between academic achievement (mathematics and literacy skills at 54 months,) and EF (working memory, inhibition, and planning) and academic achievement (mathematics and literacy skills) at age 15 ?

\section{Method}

\section{Participants}

Data for this study were drawn from the NICHD Study of Early Child Care (SECC), a comprehensive longitudinal study initiated by The National Institute of Child Health and Human 
Development (NICHD) in 1989 to answer questions about the relationship between child care experiences and children's developmental outcomes (information on the sample was adapted from information provided at https://www.nichd.nih.gov/research/supported/seccyd/Pages/overview.aspx). Throughout 1991, the project recruited mothers from hospitals near the following locations: Little Rock, AK; Irvine, CA; Lawrence, KA; Boston, MA; Philadelphia, PA; Pittsburgh, PA; Charlottesville, VA; Morganton, NC; Seattle, WA; and Madison, WI. Potential participants were selected from among 8,986 mothers giving birth during selected 24-hour sampling periods using a conditional random sampling plan which was designed to recruit families who were demographically diverse (in income, education, marital status, and race) and who had various types of child care plans after birth (stay at home, go back to work full-time, go back to work part-time). The sample of 8,986 mothers was reduced to 5,416 mothers eligible for a phone call two weeks after the birth due to factors such as unplanned attrition, mother younger than 18 years of age, multiple births, mother not fluent in English, and medical complications. The sample was not intended to be nationally representative, but was designed to represent healthy births to non-teen parents at the selected hospitals. Recruitment was attempted with a randomly selected subset of 3,015 families and about half of the families $(n=1364)$ consented. Of these families that consented to the study $80 \%$ are White, $13 \%$ Black, 2\% Asian, and 5\% are Pacific Islander or Other. For the present analyses, the sample was restricted to the two largest race groups, White and Black $(N=1273)$. The means, standard deviations, range, and percent missing of all study variables are presented in Table 1.

\section{Measures}


Executive function skills. The NICHD-SEECYD contained multiple measures of children's EF skills. Early EF skills were measured in the lab at 54 months and first grade, and later EF skills were measured at age 15. Early EF skills included delay of gratification, working memory, sustained attention, and inhibition assessed at 54 months. Later EF skills assessed at age 15 included planning, working memory, and inhibition.

Delay of gratification. The Delay of Gratification task (Mischel, 1974) requires children to sit in front of a larger and smaller portion of a treat (depending on what the child likes) and wait for a 7-minute period. The child has the option of waiting the full time period for the larger food treat or of getting a smaller treat sooner. Delay of gratification was measured as the length of time the child waited to receive the reward $(M=4.53, S D=3.00)$. Evidence for validity of this task comes from a longitudinal investigation showing that preschoolers who were able to delay gratification for a longer period of time exhibited more self-regulatory and coping competence during adolescence (Shoda, Mischel \& Peake, 1990).

Working memory. Early working memory was assessed at 54 months using the W-score of the Woodcock-Johnson Psycho-educational Battery - Revised Memory for Sentences task (Woodcock \& Johnson, 1989). In this task, children listen to words, phrases, and sentences, and must recall them $(M=457.20, S D=18.42 ; \alpha=.86-.94)$. Later working memory was assessed at age 15 using the Numbers and Letters task (OSPAN; Turner \& Engle, 1989). In this task, adolescents recall a series of letters between completing a set of calculations. Working memory was measured as the total number of letters identified correctly within a trial $(M=32.27, S D=$ 17.14).

Sustained attention. The Continuous Performance Task (CPT) designed for young children (Rosvold, Mirsky, Sarason, Bransome, \& Beck, 1956) was used to measure early 
sustained attention at 54 months. The task involves viewing pictures of common objects on a computer screen and pressing a button when a target stimulus appears. The average reaction time and errors were coded across time so that decrements in performance can be computed as an indication of sustained attention. In this study, the number of times the child did not press a button when the target stimulus appeared was used as the measure of sustained attention $(M=$ 9.13, $S D=7.58)$. The CPT has demonstrated adequate test-retest reliability $(\mathrm{r}=.65-.74)$ and very good predictive validity, including measures of school achievement and cognitive functioning in school-aged children (Halperin, Sharma, Greenblat, \& Schwartz, 1991).

Inhibition. Children's inhibition was measured using a variation of the Children's Stroop task (Gerstadt, Hong, \& Diamond, 1994). This adaptation requires children to respond to cards with nighttime scenes (stars \& moon) with the word day and to respond to cards with a daytime picture (the sun) with the word night. Inhibition was measured using the percentage of incorrect responses $(M=25.39, S D=20.63)$. The Stroop Test, one of the most frequently used measures of inhibitory control (MacLeod, 1991), was used to measure inhibition at age 15. For this task, adolescents were asked to press a button that matched the color of a word appearing on a screen while ignoring what the word says (Stroop, 1935). The interference score calculated by NICHDSEECYD was used to represent inhibition so that lower scores indicate less interference and greater inhibition skills $(M=0.09, S D=0.07)$.

Planning. Planning was measured at age 15 using the Tower of London assessment (Berg \& Byrd, 2002). In this task, adolescents were asked to move three balls on a computer screen to match a configuration shown on the computer screen in the fewest number of moves. The total percent of trials solved was used to measure adolescents' planning skills $(M=94.44$, $S D=8.92)$. 
Academic achievement. Children's early academic and cognitive skills, and later literacy and math achievement were measured using the $\mathrm{W}$ - scores of four subscales of the Woodcock-Johnson Revised (WJ-R) Tests of achievement. Internal consistency ranged from the high .80 s to the $.90 \mathrm{~s}$ across both time points. The WJ-R also has excellent predictive validity across the lifespan (McGrew, 1993) and is highly correlated with other tests of cognitive abilities and achievement (McGrew, Werder, \& Woodcock, 1991). Literacy was measured using the Picture Vocabulary subscale at 54 months $(M=459.70, S D=14.12)$ and age $15(M=518.66, S D$ $=13.08)$, and the Verbal Analogies $(M=525.75, S D=14.14)$, and Passage Comprehension $(M=$ $520.49, S D=12.57)$ subscales at age 15 . The Picture Vocabulary scale measured recognition and naming of familiar objects, and the Verbal Analogies subscale had children select a picture of objects that best completed an analogy. The Passage Comprehension subscale required children to identify a missing keyword that would make sense in the context of a written passage. Math achievement was measured using the Applied Problems subscale at 54 months $(M=424.82, S D$ $=19.24)$ and at age $15(M=524.66, S D=16.69)$. The Applied Problems subscale asked children to perform math calculations in response to problems presented orally and visually.

Child, maternal, and household covariates. A set of child-, maternal-, and householdlevel covariates related to children's EF skills and achievement were included in the model to control for their potentially confounding influence. Child-level covariates included race (13.83\% Black) and gender (52\% male), and whether the child was ever in child care from birth to age 53 months (75.96\% had ever attended child care). Given that maternal education and income are related to children's EF skills and achievement (e.g., Davis-Kean, 2005; Davis-Kean \& Sexton, 2009; Raver, Blair, \& Willoughby, 2013), mothers' years of education at the time of the child's birth $(M=14.97, S D=2.61)$ and an average of household income-to-needs when the child was 
1-54 months $(M=3.40, S D=2.65)$ were included as covariates. Total household size $(M=4.27$, $S D=1.15)$ when child was 54 months and child's age in months $(M=4.64, S D=0.09)$ were included in the model as well.

Home environment. The Home Observation for Measurement of the Environment (HOME) Inventory (Caldwell \& Bradley, 1984) was administered in the home by trained researchers when children were aged 54 months. The HOME Inventory is a semi-structured observation and interview tool designed to gather information on various aspects of the child's home environment. We used the total HOME score in our analyses $(M=46.08, S D=5.45)$. Interobserver agreement was greater than $90 \%$ and the alpha coefficient for the total score is .93 .

\section{Analytic Strategy}

The sample had a low to moderate amount of missing data with the highest amount of data missing primarily at age 15 (ranging from $31-35 \%$ ). About $31 \%$ of the sample had missing data on all study outcomes at age 15 . Children who were Black, never in child care, from families with lower income and educational backgrounds were more likely to have data missing at age 15 than their counterparts. There were also significant differences by site. Children from site 8 were less likely to have data missing in comparison to children from other sites. Children from sites $0,1,2$, and 4 were more likely to have data missing at age 15 compared to their counterparts. In contrast, no significant differences in missing data by child gender, number of children in the household, or child age were detected. Listwise deletion of variables is considered the most biased of missing data techniques to use especially when rich, longitudinal data is available for multiple imputations (Allison, 2002; Widaman, 2006). Thus, we used the full information from the data set to help in adjusting for the missing information in this study and meet the criteria for missing at random (MAR) by including the variables in the imputations that 
were related to missingness in our analyses. Missing data were imputed using multiple imputations by chained equations procedures in Stata 14 to create 25 complete datasets. In this procedure, missing values are imputed based on the values and associations observed for each individual and across all participants in the sample (Schafer \& Graham, 2002). In Stata, the chained equations procedure uses a series of conditional regression models to impute data beginning with variables with the least amount of missing data to the most. All the variables in the study were included in our imputation model and both observed and imputed values were used to estimate missing values. Missing values for continuous variables were estimated using regression and missing values for dichotomous variables were estimated using logistic regression. All variables were transformed into z-scores prior to running analyses so that all variables are on the same metric and can be interpreted with ease.

Multiple regression analyses for each set of EF and achievement outcomes were estimated hierarchically in three steps. In the first model, EF at age 15 was regressed on early $\mathrm{EF}$, and in the second model, EF at age 15 was regressed on early EF and early achievement. The third model added covariates: the focal child's race and gender, whether the focal child ever attended child care, maternal education at the focal child's birth, average household income during the first 54 months of the focal child's life, total household size when the focal child was 54 months old, child age in months, and the home environment measured at age 54 months. All analyses were clustered by site to account for any potential biases due to nesting.

Standard error adjustments were incorporated in all models to take into account the possibility of intragroup correlation of individuals by site. To reduce the possibility of Type I errors due to multiple comparisons, Holm (Holm, 1979) and Bonferroni corrections were applied to the final models. 


\section{Results}

Table 2 displays the results from the models predicting executive functioning skills at age 15 and achievement at age 15, respectively. Except where noted, below we describe the results with the Holm's correction, which adjusts for multiple comparisons but is less conservative in comparison to the Bonferroni correction (Holm, 1979).

\section{Predicting EF at age 15}

As evident in Table 2, none of the early EF skills measured at 54 months significantly predicted planning or inhibition at age 15. Early working memory, however, predicted later working memory in model 1 and remained significant, with the size of the coefficient decreasing slightly from .28 to .21 when early achievement was added in model 2 . In model 3, early working memory continued to be a significant predictor of later working memory with no changes in coefficient size after sociodemographic covariates were added and after applying the more conservative Bonferroni correction $(b=.21, p=.006)$; a one standard deviation increase in children's working memory at 54 months predicted a .21 standard deviation increase in working memory at age 15 after holding constant everything else in the model.

Early achievement did not significantly predict later EF except for later working memory. Specifically Applied Problems measured at 54 months significantly predicted working memory at age 15 after holding all sociodemographic covariates constant $(b=.18, p=0.02)$; a one standard deviation increase in early applied problems score was associated with a .18 standard deviation increase in later working memory. In contrast, early Picture Vocabulary did not significantly predict any EF skills measured at age 15 .

Across all the models predicting later EF, the adjusted R-square statistics ranged from .01 to .19, which indicate that these models are predicting little of the variance in EF skills measured 
at age 15. As expected, the models predicting the most variance in later EF predicted 13 to $19 \%$ of the variance in working memory measured at age 15.

\section{Predicting Achievement at age 15}

The majority of the early EF skills were significant predictors of later achievement when no covariates were included in the model (see Table 3). In model 1, early delay of gratification and working memory predicted all achievement at age 15 , and early sustained attention predicted all later achievement except for Picture Vocabulary at age 15. In contrast, early impulsivity was a weak predictor of later achievement. It did not predict any of the later achievement outcomes except for Verbal Analogies at age $15(b=-.13, p=.03)$. A one standard deviation increase in impulsivity measured at 54 months was associated with a .13 standard deviation decrease in Verbal Analogies assessed at age 15.

Once early achievement was added to the model, there were large increases in the adjusted R-squared statistics between models 1 and 2 across all achievement outcomes. Most of the early EF skills, however, became non-significant predictors of later achievement once early achievement was added. The only exception to this pattern was early working memory $(b=.12$, $p=.03$ ), which remained a significant predictor of later Passage Comprehension even with prior achievement in the model. Importantly, even when all other covariates were added in model 3, early working memory remained a statistically significant predictor; a one standard deviation increase in working memory at age 54 months was associated with a .12 standard deviation increase in Passage Comprehension at age 15 after accounting for all other covariates in the model.

As expected, both measures of early achievement robustly predicted later achievement. Importantly, the magnitude of the association between early and later achievement (range: .20- 
.39 ) is larger than the association between early EF and later achievement (early working memory and later Passage Comprehension: $b=.12$ ) the association between early EF and later EF (range: .18-.21).

Though not the focus of primary questions of the study, it is noted that none of the sociodemographic covariates were significant predictors of EF assessed at age 15. Several covariates (race, gender, and maternal education) significantly predicted achievement at age 15 . Higher maternal education when the child was 54 months, for example, predicted higher achievement in all subscales assessed at age 15, and this relationship remained consistent in size even after the Holm's and Bonferroni corrections.

\section{Discussion}

The purpose of this study was to assess longitudinal associations among executive function (EF) components in early childhood (54 months) and adolescence (15 years) and their prediction of academic achievement while holding important demographic and early home environment variables constant. We found that among all EF components, only working memory at 54 months significantly predicted working memory at 15 years and that working memory was the only significant EF predictor of achievement at age 15. In contrast, all early achievement measures were significant predictors of later achievement. Further, no demographic or home environment variables at 54 months significantly predicted EF at 15, and only maternal education significantly explained variance in adolescent math and literacy achievement at 15 . These findings demonstrate the important role that working memory has in predicting later memory measures as well as academic outcomes across development. However, the lack of associations of inhibition and attention measures to corresponding measures in adolescence may suggest either lack of developmentally sensitive measures of EF or that these measures are not 
stable predictors across time. Unlike published achievement measures, many psychological and educational measures are not validated across the population or across the lifespan. They are often designed for a specific study or population and the psychometric properties have not been well assessed. Recently, researchers have tried to deal with this issue by standardizing these assessments in a common "toolbox" of measures (Weintraub, et al., 2013) but the use of these cognitive measures continues to be limited across developmental and educational research. Given that the EF measures used in the NICHD-SECCYD are still commonly used in educational and psychological research, more care should go into understanding the psychometric properties of these measures across development.

\section{Associations Among EF Measures Across Development}

Despite a growing body of literature demonstrating longitudinal associations and predictability among EF measures (e.g., Harms et al., 2014; Boelema et al., 2014; Wiebe, Sheffield, \& Espy, 2012), only working memory significantly predicted later working memory in our final models. No other early EF skills measured at 54 months significantly predicted EF at age 15. This is a significant departure from the findings in the literature. However, studies that have demonstrated longitudinal stability in EF focus on relatively short intervals of time and/or do not examine changes across major developmental periods. The present findings suggest that EF constructs in adolescence as measured in this study might be distinct from EF in young children, given the lack of significant associations from early childhood to adolescence. Since EF undergoes major reorganization during late childhood and early adolescence (Brydges, Reid, Fox, \& Anderson, 2014; Usai, Viterbori, Traverso, \& De Franchis, 2014), more work is needed to understand the precise timing of differentiation of EF components, and the implications that has on how we conceptualize and measure EF across development. The lack of significant 
associations between measures of inhibition and attention in early childhood and adolescence provides preliminary evidence that these measures might be capturing distinct cognitive properties during these two major developmental stages, and indicates measurement variance over time. Together, these findings suggest that more psychometric work is needed to develop and validate developmentally sensitive measures of EF across development.

It is important to note that our interpretation of the predictability of EF across time remains limited. Despite examining links between children's performance across two assessments, we are unable to make strong inferences regarding specific timing of componential differentiation or protracted maturation. Understanding the precise developmental timing of EF growth would require longitudinal data with three or more time points, including several measures per component. This design would allow us to characterize developmental changes in EF throughout development. Furthermore, with multiple measures per component, future research could employ factor analytic techniques to assess the structure of EF over time. Together, this will provide the most compelling approach toward understanding the development of EF and identifying developmentally appropriate measures across developmental stages.

\section{Longitudinal Associations among EF and Achievement}

Early math skills predicted working memory at age 15 even after applying the most conservative correction for multiple comparisons. Working memory at 54 months significantly predicted academic skills at age 15. No other early EF measure significantly predicted academic achievement at age 15 . This finding reinforces a large body of literature that underscores the importance of early working memory skills for academic achievement. However, the lack of prediction of early measures of attention and inhibition to later achievement after controlling for individual and demographic-level covariates is a departure from the literature, and points to the 
limited longitudinal predictability of these constructs across a wide range of years. Further, the lack of association between delay of gratification at 54 months and academic achievement at age 15 replicates the recent findings by Watts, Duncan, and Quan (2018), who reported a significantly reduced association between early delay of gratification and later academic achievement in the presence of controls for family background, early cognitive ability, and the home environment. These findings suggest that among EF components, working memory most strongly predicts academic skills and this prediction is maintained throughout adolescence. In contrast to the limited longitudinal predictions from early measures of EF to adolescent achievement, all early achievement measures were significant predictors of later achievement after controlling for family background, early cognitive ability, and the home environment. Together, these results point to our ability to predict academic outcomes in adolescence using child-level predictors as early as 54 month of age, and also highlight the longterm importance of early working memory for children's academic achievement.

\section{Demographic and Home Environment Predictors of EF and Achievement}

Many covariates were used that may help explain the associations among the EF and achievement variables across the longitudinal span. Though not the primary focus of the study, it was surprising that no demographic or home environment variables predicted EF at age 15 . Although previous studies have found associations between various demographic and home predictors and measures of early EF (Blair, 2010; Hackman, Gallop, Evans, \& Farah, 2015; Sarsour et al., 2011), the current study provides no evidence for longitudinal links to EF in adolescence. Rather, early EF and math performance account for differences in EF performance at age 15 after controlling for demographic and contextual predictors. This indicates that earlier cognitive and academic skills may be the best predictors of later EF performance and that early 
contextual factors have little additional predictive value. Future research should investigate how these associations may vary when incorporating measures of EF and context at different time points.

No demographic or home environment variables at 54 months significantly predicted academic achievement at 15 in our final models, and only maternal education significantly explained variance in adolescent math and literacy achievement. Consistent with the literature (Bradley \& Corwyn, Davis-Kean, 2005) maternal education is an important predictor of achievement outcomes across development. Somewhat surprising was the lack of prediction to $\mathrm{EF}$, especially working memory, which is related to achievement. Also, as noted previously, there are other studies that have found links between home environment variables to achievement in early and middle childhood, but these findings suggest that they do not extend to adolescence. Given that we found significant correlations between early demographic and home environment variables and later cognitive and academic skills before including covariates it could be that the characteristics of the home environment such as cognitive stimulation and warmth have the most influence early in development and their impact on later academic and cognitive skills is mediated by earlier academic and cognitive skills. Future research should examine the pathways through which early demographic and home environment variables influence adolescent academic and cognitive skills.

\section{Limitations and Future Direction}

There are several limitations to the current study and its findings. First, despite the strength of the longitudinal design, this study lacked the type of design needed to identify causal links between variables. Although several important covariates were entered in the final models, unmeasured variables might still account for the observed effects. Secondly, although these data 
come from a large, national database, they are not nationally representative of the population, which limits the generalizability of our findings. Third, since the time points in the current study spanned early childhood and adolescence, EF components were measured using different assessments across time, which can partially account for the lack of significant associations among early and later EF measures. It is also important to note that the obtained effects sizes are relatively small for psychological phenomena. However, we were interested in understanding the effects of individual subcomponents of larger cognitive constructs - aggregate effects of composite or latent variables would have yielded larger effect sizes. Additionally, these effects were observed over a ten-year period, which suggests their longitudinal importance. Finally, attrition is inherent to any longitudinal data, which may lead to biased study results. With the use of complex data, we were able to address this issue by including covariates in our multiple imputation models, which is the recommended alternative to listwise deletion and best practice for missing data (Allison, 2002; Widaman, 2006).

\section{Conclusion}

In sum, the associations among measures of working memory and academic achievement from 54 months to 15 years represent our remarkable ability to predict adolescent cognition and performance from single measurements as early as 54 months. However, measures of attention and inhibition in our models did not significantly predict later EF or academic performance. The achievement measures used in this study have been constructed and validated across the population and across a large developmental age range. Years of psychometric work has gone into standardizing and age-norming Woodcock-Johnson tests of achievement - this degree of evaluation has not been applied to EF measures across development. Given that EF undergoes significant reorganization across development (Lee, Bull, \& Ho, 2013; Shing, Lindenberger, 
Diamond, Lee, \& Davidson, 2010), more work is needed to understand the precise timing of differentiation in order to construct and validate developmentally appropriate EF measures. This lack of developmentally sensitive EF measures hinders our understanding of EF growth, and the degree to which its components contribute to developmental and academic outcomes. It is important that future research take steps to address this fundamental measurement issue. Given that the EF measures in our sample are commonly used in educational and psychological research and practice, more care should go into understanding the psychometric properties across development. This will help to understand whether commonly used EF measures tap into the same underlying cognitive skill across development. 


\section{References}

Adams, A., Bourke, L., \& Willis, C. (1999). Working memory and spoken language comprehension in young children. International Journal of Psychology, 34(5-6), 364373. doi:10.1080/002075999399701

Adler, N. E., \& Rehkopf, D. H. (2008). U.S. disparities in health: Descriptions, causes, and mechanisms. Annual Review of Public Health, 29235-252.

doi:10.1146/annurev.publhealth.29.020907.090852

Allison, P. D. (2002). Missing data: Quantitative applications in the social sciences. British Journal of Mathematical and Statistical Psychology, 55(1), 193-196. doi: $10.1348 / 000711002159653$

Altemeier, L., Jones, J., Abbott, R. D., \& Berninger, V. W. (2006). Executive functions in becoming writing readers and reading writers: Note taking and report writing in third and fifth graders. Developmental Neuropsychology, 29(1), 161-173. doi:10.1207/s15326942dn2901_8

Anderson, P. (2002). Assessment and development of executive function (EF) during childhood. Child Neuropsychology, 8(2), 71-82. doi:10.1076/chin.8.2.71.8724

Berg, W. K., \& Byrd, D. L. (2002). The Tower of London spatial problem-solving task: Enhancing clinical and research implementation. Journal of Clinical and Experimental Neuropsychology, 24(5), 586-604. doi:10.1076/jcen.24.5.586.1006

Bernier, A., Carlson, S. M., Deschênes, M., \& Matte-Gagné, C. (2012). Social factors in the development of early executive functioning: A closer look at the caregiving environment. Developmental Science, 15(1), 12-24. doi:10.1111/j.14677687.2011.01093.x 
Best, J. R., Miller, P. H., \& Naglieri, J. A. (2011). Relations between executive function and academic achievement from ages 5 to 17 in a large, representative national sample. Learning and Individual Differences, 21(4), 327-336.

doi:10.1016/j.lindif.2011.01.007

Blair, C. (2002). School readiness: Integrating cognition and emotion in a neurobiological conceptualization of children's functioning at school entry. American Psychologist, 57(2), 111-127. doi:10.1037/0003-066X.57.2.111

Blair, C. (2010). Stress and the development of self-regulation in context. Child Development Perspectives, 4(3), 181-188. doi:10.1111/j.1750-8606.2010.00145.x

Blair, C., Raver, C. C., \& Berry, D. J. (2014). Two approaches to estimating the effect of parenting on the development of executive function in early childhood. Developmental Psychology, 50(2), 554-565. doi:10.1037/a0033647

Blair, C., \& Razza, R. P. (2007). Relating effortful control, executive function, and false belief understanding to emerging math and literacy ability in kindergarten. Child Development, 78(2), 647-663. doi:10.1111/j.1467-8624.2007.01019.x

Blums, A., Belsky, J., Grimm, K., \& Chen, Z. (2017). Building links between early socioeconomic status, cognitive ability, and math and science achievement. Journal of Cognition and Development, 18(1), 16-40. doi:10.1080/15248372.2016.1228652

Boelema, S. R., Harakeh, Z., Ormel, J., Hartman, C. A., Vollebergh, W. M., \& van Zandvoort, M. E. (2014). Executive functioning shows differential maturation from early to late adolescence: Longitudinal findings from a TRAILS study. Neuropsychology, 28(2), 177187. doi:10.1037/neu0000049 
Bradley, R. H., \& Corwyn, R. F. (2005). Caring for children around the world: A view from HOME. International Journal of Behavioral Development, 29(6), 468-478. doi:10.1080/01650250500146925

Brito, N. H., \& Noble, K. G. (2014). Socioeconomic status and structural brain development. Frontiers in Neuroscience, 8, 1-12. doi:10.3389/fnins.2014.00276

Brydges, C. R., Reid, C. L., Fox, A. M., \& Anderson, M. (2012). A unitary executive function predicts intelligence in children. Intelligence, 40(5), 458-469. doi:10.1016/j.intell.2012.05.006

Bull, E., \& Lee, K. (2014). Executive functioning and mathematics achievement. Child Development Perspectives, 8(1), 36-41. doi: 10.1111/cdep.12059

Bull, R., \& Scerif, G. (2001). Executive functioning as a predictor of children's mathematics ability: Inhibition, switching, and working memory. Developmental Neuropsychology, 19(3), 273-293. doi:10.1207/S15326942DN1903_3

Cartwright, K. B. (2012). Insights from cognitive neuroscience: The importance of executive function for early reading development and education. Early Education and Development, 23(1), 24-36. doi:10.1080/10409289.2011.615025

Caldwell, B. \& Bradley, B. (1984). Home Observation for Measurement of the Environment. Little Rock, AR: University of Arkansas at Little Rock.

Conger, R. D., \& Donnellan, M. B. (2007). An interactionist perspective on the socioeconomic context of human development. Annual Review of Psychology, 58, 175-199. doi:10.1146/annurev.psych.58.110405.085551

Davis-Kean, P. E. (2005). The influence of parent education and family income on child achievement: The indirect role of parental expectations and the home 
environment. Journal of Family Psychology, 19(2), 294-304. doi:10.1037/08933200.19.2.294

Davis-Kean, P. E. \& Sexton, H. R. (2009). Race differences in parental influences on child achievement: Multiple pathways to success. Merrill-Palmer Quarterly 55(3), 285-318. doi:10.1353/mpq.0.0023

Dearing, E., \& Tang, S. (2010). The home learning environment and achievement during childhood. In S. Christenson \& A. L. Reschly (Eds.), Handbook on school-family partnerships (pp.131-157). New York, NY: Taylor \& Francis.

Diamond, A., \& Lee, K. (2011). Interventions shown to aid executive function development in children 4 to 12 years old. Science, 333(6045), 959-964. doi:10.1126/science.1204529

Duncan, G. J., Dowsett, C. J., Claessens, A., Magnuson, K., Huston, A. C., Klebanov, P., \& ... Japel, C. (2007). School readiness and later achievement. Developmental Psychology, 43(6), 1428-1446. doi:10.1037/0012-1649.43.6.1428

Espy, K. A., Bull, R., Kaiser, H., Martin, J., \& Banet, M. (2008). Methodological and conceptual issues in understanding the development of executive control in the preschool period. In V. Anderson, R. Jacobs, P. J. Anderson (Eds.), Executive functions and the frontal lobes: A lifespan perspective (pp. 105-121). Philadelphia, PA: Taylor \& Francis.

Farah, M. J. (2017). The neuroscience of socioeconomic status: Correlates, causes, and consequences. Neuron, 96, 56-71. doi:10.1016/j.neuron.2017.08.034

Fay-Stammbach, T., Hawes, D. J., \& Meredith, P. (2014). Parenting influences on executive function in early childhood: A review. Child Development Perspectives, 8(4), 258-264. doi:10.1111/cdep.12095 
Friso-van den Bos, I., Van der Ven, S. H. G., Kroesbergen, E. H., \& Van Luit, J. E. H. (2014). Working memory and mathematics in primary school children: A meta-analysis. Educational Research Review, 10, 29-44. doi: 10.1016/j.edurev.2013.05.003

Fuhs, M. E., \& Day, J. D. (2011). Verbal ability and executive functioning development in preschoolers at Head Start. Developmental Psychology, 47, 404-416. doi:10.1037/ $\mathrm{a} 0021065$

Gathercole, S. E., \& Pickering, S. J. (2000). Working memory deficits in children with low achievements in the national curriculum at 7 years of age. British Journal of Educational Psychology, 70(2), 177-194. doi:10.1348/000709900158047

Geoffroy, M., Côté, S. M., Giguère, C. É., Dionne, G., Zelazo, P. D., Tremblay, R. E., \& ... Séguin, J. R. (2010). Closing the gap in academic readiness and achievement: The role of early childcare. Journal of Child Psychology and Psychiatry, 51(12), 1359-1367. doi:10.1111/j.1469-7610.2010.02316.x

George, J. L., \& Greenfield, D. B. (2005). Examination of a structured problem-solving flexibility task for assessing approaches to learning in young children: Relation to teacher ratings and children's achievement. Journal of Applied Developmental Psychology, 26(1), 69-84. doi:10.1016/j.appdev.2004.10.006

Gerstadt, C. L., Hong, Y. J., \& Diamond, A. (1994). The relationship between cognition and action: Performance of children 3 1/2-7 years old on a Stroop-like day-night test. Cognition, 53(2), 129-153. doi:10.1016/0010-0277(94)90068-X

Hackman, D. A., Gallop, R., Evans, G. W., \& Farah, M. J. (2015). Socioeconomic status and executive function: Developmental trajectories and mediation. Developmental Science, 18(5), 686-702. doi:10.1111/desc.12246 
Hackman, D. A., \& Farah, M. J. (2009). Socioeconomic status and the developing brain. Trends in Cognitive Sciences, 13(2), 65-73. doi:10.1016/j.tics.2008.11.003

Halperin, J. M., Sharma, V., Greenblatt, E., \& Schwartz, S. T. (1991). Assessment of the Continuous Performance Test: Reliability and validity in a nonreferred sample. Psychological Assessment: A Journal of Consulting and Clinical Psychology, 3(4), 603-608. doi:10.1037/1040-3590.3.4.603

Harms, M. B., Zayas, V., Meltzoff, A. N., \& Carlson, S. M. (2014). Stability of executive function and predictions to adaptive behavior from middle childhood to pre-adolescence. Frontiers in Psychology, 5, 1-11. doi: 10.3389/fpsyg.2014.0033

Hitch, G. J., Towse, J. N., \& Hutton, U. (2001). What limits children's working memory span? Theoretical accounts and applications for scholastic development. Journal of Experimental Psychology, 130(2), 184-198. doi:10.1037/0096-3445.130.2.184

Holm, S. (1979). A simple sequentially rejective multiple test procedure. Scandinavian Journal of Statistics, 6, 65-70.

Hughes, C. (1998). Executive function in preschoolers: Links with theory of mind and verbal ability. British Journal of Developmental Psychology, 16(2), 233-253. doi:10.1111/j.2044-835X.1998.tb00921.x

Hughes, C., Ensor, R., Wilson, A., \& Graham, A. (2010). Tracking executive function across the transition to school: A latent variable approach. Developmental Neuropsychology, 35(1), 20-36. doi:10.1080/87565640903325691

Hughes, C., \& Ensor, R. (2011). Individual differences in growth in executive function across the transition to school predict externalizing and internalizing behaviors and self-perceived 
academic success at 6 years of age. Journal of Experimental Child Psychology, 108(3), 663-676. doi:10.1016/j.jecp.2010.06.005

Klahr, D., \& Robinson, M. (1981). Formal assessment of problem-solving and planning processes in preschool children. Cognitive Psychology, 13(1), 113-148. doi:10.1016/0010-0285(81)90006-2

Jacques, S., \& Zelazo, P. D. (2001). The Flexible Item Selection Task (FIST): A measure of executive function in preschoolers. Developmental Neuropsychology, 20(3), 573-591. doi:10.1207/875656401753549807

Lan, X., Legare, C. H., Ponitz, C. C., Li, S., \& Morrison, F. J. (2011). Investigating the links between the subcomponents of executive function and academic achievement: A crosscultural analysis of Chinese and American preschoolers. Journal of Experimental Child Psychology, 108(3), 677-692. doi:10.1016/j.jecp.2010.11.001

Latzman, R. D., Elkovitch, N., Young, J., \& Clark, L. A. (2010). The contribution of executive functioning to academic achievement among male adolescents. Journal of Clinical and Experimental Neuropsychology, 32(5), 455-462. doi:10.1080/13803390903164363

Lawson, G. M., Hook, C. J., \& Farah, M. J. (2017). A meta-analysis of the relationship between socioeconomic status and executive function performance among children. Developmental Science. doi:10.1111/desc.12529

Lee, K., Bull, R., \& Ho, R. M. H. (2013). Developmental changes in executive functioning. Child Development, 84(6), 1933-1953 doi: 10.1111/cdev.12096

Luciana, M., Conklin, H. M., Hooper, C. J., \& Yarger, R. S. (2005). The Development of Nonverbal Working Memory and Executive Control Processes in Adolescents. Child Development, 76(3), 697-712. doi:10.1111/j.1467-8624.2005.00872.x 
MacLeod, C. M. (1991). Half a century of research on the Stroop effect: An integrative review. Psychological Bulletin, 109(2), 163-203. doi:10.1037/0033-2909.109.2.163

McClelland, M. M., Cameron, C. E., Connor, C. M., Farris, C. L., Jewkes, A. M., \& Morrison, F. J. (2007). Links between behavioral regulation and preschoolers' literacy, vocabulary, and math skills. Developmental Psychology, 43(4), 947-959. doi:10.1037/00121649.43.4.947

McGrew, K. S., Werder, J. K., \& Woodcock, R. W. (1991). WJ-R technical manual. Allen, TX: DLM.

McGrew, K. S. (1993). The relationship between the Woodcock-Johnson Psycho-Educational Battery-Revised Gf-Gc cognitive clusters and reading achievement across the life-span. In B. A. Bracken, R. S. McCallum (Eds.), Woodcock-Johnson Psycho-Educational Battery-Revised (pp. 39-53). Brandon, VT: Clinical Psychology Publishing Co.

McLoyd, V. C. (1998). Socioeconomic disadvantage and child development. American Psychologist, 53(2), 185-204. doi:10.1037/0003-066X.53.2.185

Merz, E. C., Landry, S. H., Montroy, J. J., \& Williams, J. M. (2016). Bidirectional associations between parental responsiveness and executive function during early childhood. Social Development. doi:10.1111/sode. 12204

Mischel, W. (1974) Processes in delay of gratification. In L. Berkowitz (Ed.), Advances in experimental social psychology (Vol. 7, pp. 249-292). San Diego, CA: Academic Press.

Miller, M., \& Hinshaw, S. P. (2010). Does childhood executive function predict adolescent functional outcomes in girls with ADHD? Journal of Abnormal Child Psychology, 38(3), 315-326. doi:10.1007/s10802-009-9369-2 
Moffitt, T. E., Arseneault, L., Belsky, D., Dickson, N., Hancox, R. J., Harrington, H., . . Caspi, A. (2011). A gradient of childhood self-control predicts health, wealth, and public safety. Proceedings of the National Academy of Sciences, USA, 108, 2693-2698. doi:10.1073/pnas.1010076108

Montgomery, D. E., \& Koeltzow, T. E. (2010). A review of the day-night task: The Stroop paradigm and interference control in young children. Developmental Review, 30(3), 308330. doi:10.1016/j.dr.2010.07.001

Raver, C. C., Blair, C., \& Willoughby, M. (2013). Poverty as a predictor of 4-year-olds' executive function: New perspectives on models of differential susceptibility. Developmental Psychology, 49(2), 292-304. doi:10.1037/a0028343

Rosvold, H. E., Mirsky, A. F., Sarason, I., Bransome, E. J., \& Beck, L. H. (1956). A continuous performance test of brain damage. Journal of Consulting Psychology, 20(5), 343-350. doi:10.1037/h0043220

Samuels, W. E., Tournaki, N., Blackman, S., \& Zilinski, C. (2016). Executive functioning predicts academic achievement in middle school: A four-year longitudinal study. The Journal of Educational Research, 109(5), 478-490. doi:10.1080/00220671.2014.979913

Sarsour, K., Sheridan, M., Jutte, D., Nuru-Jeter, A., Hinshaw, S., \& Boyce, W. T. (2011). Family socioeconomic status and child executive functions: The roles of language, home environment, and single parenthood. Journal of the International Neuropsychological Society, 17(1), 120-132. doi:10.1017/S1355617710001335

Shing, Y. L., Lindenberger, U., Diamond, A., Li, S., \& Davidson, M. C. (2010). Memory maintenance and inhibitory control differentiate from early childhood to 
adolescence. Developmental Neuropsychology, 35(6), 679-697.

doi:10.1080/87565641.2010.508546

Shoda, Y., Mischel, W., \& Peake, P. K. (1990). Predicting adolescent cognitive and selfregulatory competencies from preschool delay of gratification: Identifying diagnostic conditions. Developmental Psychology, 26(6), 978-986. doi:10.1037/0012-1649.26.6.978

Shonkoff, J. P., \& Phillips, D. A. (2000). From neurons to neighborhoods: The science of early childhood development. Washington, DC: National Academy Press.

Sirin, S. R. (2005). Socioeconomic status and academic achievement: A meta-analytic review of research. Review of Educational Research, 75(3), 417-453. doi: $10.3102 / 00346543075003417$

Smidts, D. P., Jacobs, R., \& Anderson, V. (2004). The object classification task for children (OCTC): A measure of concept generation and mental flexibility in early childhood. Developmental Neuropsychology, 26(1), 385-401. doi:10.1207/s15326942dn2601_2

St Clair-Thompson, H. L., \& Gathercole, S. E. (2006). Executive functions and achievements in school: Shifting, updating, inhibition, and working memory. The Quarterly Journal of Experimental Psychology, 59(4), 745-759. doi:10.1080/17470210500162854

Stipek, D., \& Valentino, R. A. (2015). Early childhood memory and attention as predictors of academic growth trajectories. Journal of Educational Psychology, 107(3), 771.

Streiner, D. L. (2003). Starting at the beginning: An introduction to coefficient alpha and internal consistency. Journal of Personality Assessment, 80(1), 99-103. doi:10.1207/S15327752JPA8001_18 
Stroop, J. R. (1935). Studies of interference in serial verbal reactions. Journal of Experimental Psychology, 18(6), 643-662. doi:10.1037/h0054651

Turner, M. L., \& Engle, R. W. (1989). Is working memory capacity task dependent? Journal of Memory and Language, 28, 127-154. doi: 10.1016/0749-596X(89)90040-5

Usai, M. C., Viterbori, P., Traverso, L., \& De Franchis, V. (2014). Latent structure of executive function in five- and six-year-old children: A longitudinal study. European Journal of Developmental Psychology, 11(4), 447-462. doi:10.1080/17405629.2013.840578

van der Sluis, S., de Jong, P. F., \& van der Leij, A. (2007). Executive functioning in children, and its relations with reasoning, reading, and arithmetic. Intelligence, 35(5), 427-449. doi:10.1016/j.intell.2006.09.001

Watts, T. W., Duncan, G. J., \& Quan, H. (2018). Revisiting the Marshmallow Test: A conceptual replication investigating links between early delay of gratification and later outcomes. Psychological Science, 1-19, doi:10.177/0956797618761661

Welsh, J. A., Nix, R. L., Blair, C., Bierman, K. L., \& Nelson, K. E. (2010). The development of cognitive skills and gains in academic school readiness for children from low-income families. Journal of Educational Psychology, 102(1), 43-53. doi:10.1037/a0016738

Widaman, K. F. (2006). Missing data: What to do with or without them. Monographs of the Society for Research in Child Development, 71, 42-64. doi: 10.1111/j.15405834.2006.00404.x

Wiebe, S. A., Sheffield, T. D., \& Espy, K. A. (2012). Separating the fish from the sharks: A longitudinal study of preschool response inhibition. Child Development, 83(4), 12451261. doi:10.1111/j.1467-8624.2012.01765.x 
Weintraub, S., Bauer, P. J., Zelazo, P. D., Wallner-Allen, K., Dikmen, S. S., Heaton, R. K., Tulsky, D. S., Slotkin, J., Blitz, D. L., Carlozzi, N. E., Havlik, R. J., Beaumont, J. L., Mungas, D., Manly, J. J., Borosh, B. G., Nowinski, C. J., \& Gershon, R. C. (2013), I. NICH Toolbox Cognition Battery (CB): Introduction and pediatric data. Monographs Society Research on Child Development, 78: 1-15. doi:10.1111/mono.12031

Willoughby, M. T., Blair, C. B., Wirth, R. J., \& Greenberg, M. (2010). The measurement of executive function at age 3 years: Psychometric properties and criterion validity of a new battery of tasks. Psychological Assessment, 22(2), 306-317. doi:10.1037/a0018708

Willoughby, M. T., Wirth, R. J., \& Blair, C. B. (2012). Executive function in early childhood: Longitudinal measurement invariance and developmental change. Psychological Assessment, 24(2), 418-431. doi:10.1037/a0025779

Woodcock, R. W., \& Johnson, M. B. (1989). Woodcock-Johnson Psycho-Educational BatteryRevised. Allen, TX: DLM Teaching Resources.

Yeniad, N., Malda, M., Mesman, J., van IJzendoorn, M. H., \& Pieper, S. (2013). Shifting ability predicts math and reading performance in children: A meta-analytical study. Learning and Individual Differences, 231-9. doi:10.1016/j.lindif.2012.10.004

Zelazo, P. D., \& Carlson, S. M. (2012). Hot and cool executive function in childhood and adolescence: Development and plasticity. Child Development Perspectives, 6(4), 354360. doi:10.1111/j.1750-8606.2012.00246.x 
Table 1. Unimputed Means, Standard Deviations, Range, and Percent Missing for Study Variables

\begin{tabular}{|c|c|c|c|c|c|c|}
\hline Variable & $\mathrm{N}$ & $\mathrm{M} / \%$ & $\mathrm{SD}$ & Min & Max & $\%$ Missing \\
\hline Planning@ age 15 & 868 & 94.44 & 8.92 & 45 & 100 & 31.81 \\
\hline Working Memory @age 15 & 851 & 32.27 & 17.14 & 0 & 75 & 33.15 \\
\hline Inhibition @ age 15 & 864 & 0.09 & 0.07 & -0.10 & 0.32 & 32.13 \\
\hline Picture Vocabulary @age 15 & 830 & 518.66 & 13.08 & 451 & 563 & 34.80 \\
\hline Verbal Analogies @ age 15 & 832 & 525.75 & 14.14 & 474 & 566 & 34.64 \\
\hline Passage Comprehension @ age 15 & 828 & 520.49 & 12.57 & 446 & 554 & 34.96 \\
\hline Applied Problems @ age 15 & 828 & 524.66 & 16.69 & 444 & 591 & 34.96 \\
\hline Delay of Gratification @ 54 mo & 907 & 4.53 & 3.00 & 0 & 7 & 28.75 \\
\hline Working Memory @54 mo & 990 & 457.20 & 18.42 & 382 & 505 & 22.23 \\
\hline Sustained Attention @ 54 mo & 942 & 9.13 & 7.58 & 0 & 41.07 & 26 \\
\hline Impulsivity (errors) @ 54 mo & 785 & 25.39 & 20.63 & 0 & 87.5 & 38.33 \\
\hline Applied Problems @54 mo & 989 & 424.82 & 19.24 & 332 & 473 & 22.31 \\
\hline Picture Vocabulary@54 mo & 995 & 459.70 & 14.12 & 370 & 497 & 21.84 \\
\hline Black & 1,273 & $13.83 \%$ & & 0 & 1 & 0 \\
\hline White & 1,273 & $86.17 \%$ & & 0 & 1 & 0 \\
\hline Male child & 1,273 & $52.00 \%$ & & 0 & 1 & 0 \\
\hline Ever in child care & 1,273 & $75.96 \%$ & & 0 & 1 & 0 \\
\hline MaternalEducation@birth & 1,273 & 14.97 & 2.61 & 8 & 21 & 0 \\
\hline Avg Household Income 1-54 mo & 1,265 & 3.40 & 2.65 & 0.13 & 23.79 & 0.63 \\
\hline Total Household Size @ 54 mo & 1,018 & 4.27 & 1.15 & 2 & 12 & 20.03 \\
\hline Child age in months & 1,003 & 4.64 & 0.09 & 4.51 & 5.07 & 21.21 \\
\hline TotalHOME score @54 mo & 983 & 46.08 & 5.45 & 18 & 55 & 22.78 \\
\hline Site 0 & 1273 & $11.63 \%$ & & 0 & 1 & 0 \\
\hline Site 1 & 1273 & $9.66 \%$ & & 0 & 1 & 0 \\
\hline Site 2 & 1273 & $9.19 \%$ & & 0 & 1 & 0 \\
\hline Site 3 & 1273 & $9.90 \%$ & & 0 & 1 & 0 \\
\hline Site 4 & 1273 & $9.35 \%$ & & 0 & 1 & 0 \\
\hline Site 5 & 1273 & $10.13 \%$ & & 0 & 1 & 0 \\
\hline Site 6 & 1273 & $10.21 \%$ & & 0 & 1 & 0 \\
\hline Site 7 & 1273 & $9.51 \%$ & & 0 & 1 & 0 \\
\hline Site 8 & 1273 & $10.92 \%$ & & 0 & 1 & 0 \\
\hline Site 9 & 1273 & $9.51 \%$ & & 0 & 1 & 0 \\
\hline
\end{tabular}


Table 2. Hierarchical Regression Models Predicting Executive Functioning at Age 15 with 25 Imputed Data Sets (N=1273)

\begin{tabular}{|c|c|c|c|c|c|c|c|c|c|c|c|c|c|c|c|c|c|c|}
\hline & \multicolumn{6}{|c|}{ Planning at age 15} & \multicolumn{6}{|c|}{ Working Memory at age 15} & \multicolumn{6}{|c|}{ Inhibition at age 15} \\
\hline & \multicolumn{2}{|c|}{ Model 1} & \multicolumn{2}{|c|}{ Model 2} & \multicolumn{2}{|l|}{ Model 3} & \multicolumn{2}{|l|}{ Model 1} & \multicolumn{2}{|c|}{ Model 2} & \multicolumn{2}{|l|}{ Model 3} & \multicolumn{2}{|l|}{ Model 1} & \multicolumn{2}{|c|}{ Model 2} & \multicolumn{2}{|l|}{ Model 3} \\
\hline & $\mathrm{b}(\mathrm{SE})$ & $\mathrm{p}$ & $\mathrm{b}(\mathrm{SE})$ & $\mathrm{p}$ & $\mathrm{b}(\mathrm{SE})$ & $\mathrm{p}$ & $\mathrm{b}(\mathrm{SE})$ & $\mathrm{p}$ & $\mathrm{b}(\mathrm{SE})$ & $\mathrm{p}$ & $\mathrm{b}(\mathrm{SE})$ & $\mathrm{p}$ & $\mathrm{b}(\mathrm{SE})$ & $\mathrm{p}$ & $\mathrm{b}(\mathrm{SE})$ & $\mathrm{p}$ & $\mathrm{b}(\mathrm{SE})$ & $\mathrm{p}$ \\
\hline Delay of Gratification @54 mo & $0.07(0.04)$ & 0.13 & $0.06(0.04)$ & 0.25 & $0.06(0.04)$ & 0.26 & $0.02(0.04)$ & 0.64 & $-0.02(0.05)$ & 0.72 & $-0.02(0.05)$ & 0.69 & $0.00(0.04)$ & 0.95 & $0.01(0.04)$ & 0.78 & $0.01(0.04)$ & 0.75 \\
\hline Working Memory @54 mo & $0.08(0.04)$ & 0.09 & $0.04(0.04)$ & 0.36 & $0.03(0.04)$ & 0.470 .28 & ***hb $(0.05)$ & 0.00 & $0.21 * *$ hb $(0.05)$ & 0.01 & $0.21 * * \mathrm{hb}(0.05)$ & 0.01 & $0.05(0.04)$ & 0.27 & $0.08(0.05)$ & 0.11 & $0.07(0.04)$ & 0.16 \\
\hline Sustained Attention @ 54 mo & $-0.02(0.03)$ & 0.68 & $0.00(0.03)$ & 0.95 & $0.00(0.03)$ & 0.90 & $-0.10(0.04)$ & 0.06 & $-0.06(0.04)$ & 0.21 & $-0.06(0.04)$ & 0.21 & $-0.05(0.04)$ & 0.31 & $-0.05(0.04)$ & 0.29 & $-0.05(0.04)$ & 0.33 \\
\hline Impulsivity (errors)@54 mo & $-0.03(0.04)$ & 0.53 & $-0.03(0.04)$ & 0.58 & $-0.02(0.04)$ & 0.67 & $-0.07(0.04)$ & 0.16 & $-0.06(0.04)$ & 0.21 & $-0.07(0.04)$ & 0.18 & $-0.02(0.04)$ & 0.65 & $-0.02(0.04)$ & 0.62 & $-0.01(0.04)$ & 0.76 \\
\hline Applied Problems @54 mo & & & $0.06(0.06)$ & 0.42 & $0.07(0.06)$ & 0.34 & & & $0.19 *^{\mathrm{h}}(0.05)$ & 0.01 & $0.18 *^{*^{\mathrm{h}}}(0.05)$ & 0.02 & & & $0.05(0.05)$ & 0.42 & $0.04(0.06)$ & 0.54 \\
\hline Picture Vocabulary @54 mo & & & $0.04(0.04)^{\prime} 0$ & 0.370 & $0.04(0.05)$ & 0.51 & & & $0.00(0.04)$ & 0.96 & $-0.01(0.04)$ & 0.85 & & & $-0.13(0.05)$ & 0.05 & $-0.11(0.05)$ & 0.09 \\
\hline Child's Ethnicity: Black & & & & & $0.07(0.05)$ & 0.22 & & & & & $-0.03(0.05)$ & 0.60 & & & & & $0.04(0.04)$ & 0.44 \\
\hline Male child & & & & & $0.03(0.04)$ & 0.44 & & & & & $0.02(0.03)$ & 0.58 & & & & & $-0.09(0.04)$ & 0.06 \\
\hline Ever in child care & & & & & $-0.03(0.05)$ & 0.60 & & & & & $-0.05(0.04)$ & 0.33 & & & & & $-0.05(0.04)$ & 0.35 \\
\hline Maternal Education @ birth & & & & & $0.04(0.05)$ & 0.41 & & & & & $0.07(0.04)$ & 0.19 & & & & & $0.01(0.04)$ & 0.76 \\
\hline Avg Household Income 1-54months & & & & & $0.02(0.04)$ & 0.58 & & & & & $-0.06(0.05)$ & 0.24 & & & & & $-0.02(0.04)$ & 0.71 \\
\hline Total Household Size @54 mo & & & & & $-0.03(0.04)$ & 0.48 & & & & & $0.00(0.04)$ & 0.92 & & & & & $-0.05(0.03)$ & 0.14 \\
\hline Child age in months & & & & & $-0.02(0.03)$ & 0.62 & & & & & $-0.04(0.03)$ & 0.32 & & & & & $0.00(0.04)$ & 0.99 \\
\hline Total HOME score @ 54 mo & & & & & $0.01(0.05)$ & 0.90 & & & & & $0.01(0.04)$ & 0.84 & & & & & $0.03(0.05)$ & 0.61 \\
\hline Constant & $0.00(0.04)$ & 1.00 & $0.00(0.04)$ & 1.00 & $0.00(0.04)$ & 1.00 & $0.00(0.03)$ & 0.99 & $0.00(0.03)$ & 0.99 & $0.00(0.03)$ & 0.99 & $0.00(0.05)$ & 1.00 & $0.00(0.05)$ & 1.00 & $0.00(0.05)$ & 0.99 \\
\hline Adjusted R-Squared Range & $0.01-0.03$ & & $0.02-0.05$ & & $0.03-0.05$ & & $0.10-0.15$ & & $0.12-0.17$ & & $0.13-0.19$ & & $0.00-0.01$ & & $0.01-0.03$ & & $0.03-0.05$ & \\
\hline
\end{tabular}

Note: All variables are $\mathrm{z}$-scores. All steps clustered by site. $\mathrm{H}$ indicates significant after Holms correction. B indicates significant after Bonferroni correction ( $\mathrm{p} \leq 0.007)$. 
Table 3. Hierarchical Regression Models Predicting Achievement at Age 15 with 25 Imputed Data Sets (N=1273)

\begin{tabular}{|c|c|c|c|c|c|c|c|c|c|c|c|c|c|c|c|c|c|c|c|c|c|c|c|c|}
\hline \multirow{3}{*}{ 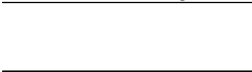 } & \multirow{2}{*}{\multicolumn{6}{|c|}{ 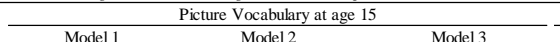 }} & \multicolumn{6}{|c|}{ Verbal Analogies at age 15} & \multicolumn{6}{|c|}{ Passage Comprehension at age 15} & \multirow{2}{*}{\multicolumn{6}{|c|}{ Applied Problems at age 15}} \\
\hline & Model 1 & & Model2 & & Model 3 & & Model 1 & & Model 2 & & Model 3 & & Model 1 & & Model 2 & & Model 3 & & $\begin{array}{l}\text { Model } 11 \\
\end{array}$ & & & & & \\
\hline & $\mathrm{b}(\mathrm{SE})$ & $\mathrm{p}$ & b(SE) & $p$ & $\mathrm{~b}(\mathrm{SE})$ & $p$ & $\mathrm{~b}(\mathrm{SE})$ & $p$ & $\mathrm{~b}(\mathrm{SE})$ & $p$ & & $p$ & $\mathrm{~b}(\mathrm{SE})$ & $p$ & & $p$ & $\mathrm{~b}(\mathrm{SE})$ & $\mathrm{p}$ & $\mathrm{b}(\mathrm{SE})$ & $\mathrm{p}$ & $\mathrm{b}(\mathrm{SE})$ & $p$ & $\mathrm{~b}(\mathrm{SE})$ & \\
\hline Delay of Gratification @54 mo & $0.15^{* h}(0.05)$ & 0.02 & $0.05(0.04)$ & 0.28 & $-0.01(0.03)$ & 0.87 & $0.16^{*}(0.05)$ & 0.02 & $0.05(0.04)$ & 0.25 & $0.02(0.04)$ & 0.67 & $0.20^{* * \mathrm{k}}(0.05)$ & 0.01 & $0.10(0.04)$ & 0.05 & $0.06(0.03)$ & 0.12 & $0.06^{* * \mathrm{hb}^{\mathrm{hb}}}(0.02)$ & 0.01 & $0.09(0.04)$ & 0.06 & $0.06(0.03)$ & 0.15 \\
\hline Working Memory @54 mo & $0.30^{* * \text { hb }}(0.04)$ & 0.00 & $0.05(0.03)$ & 0.22 & $0.06(0.03)$ & 0.160 . & $.26^{* * * *^{\text {bb }}}(0.04)$ & 0.00 & $0.05(0.04)$ & 0.26 & $0.05(0.04)$ & 0.230 & $0.33^{* * * * \text { hb }}(0.04)$ & 0.00 & $0.12^{*}(0.04)$ & 0.03 & $0.12^{* \mathrm{kh}}(0.04)$ & 0.030 & $0.26^{* * * * \text { *hb }}(0.03)$ & 0.00 & $0.06(0.04)$ & 0.17 & $0.06(0.04)$ & 0.16 \\
\hline Sustained Attention @54 mo & $-0.06(0.04)$ & 0.22 & $0.04(0.04)$ & 0.35 & $0.04(0.03)$ & 0.24 & $-0.13 *(0.04)$ & 0.02 & $-0.03(0.04)$ & 0.49 & $-0.02(0.03)$ & 0.59 & $-0.10^{*^{\mathrm{h}}}(0.04)$ & 0.05 & $0.00(0.04)$ & 0.93 & $0.00(0.04)$ & 0.96 & $5-0.12^{* \text { thb }}(0.03)$ & 0.01 & $-0.02(0.04)$ & 0.54 & $-0.02(0.03)$ & 0.64 \\
\hline Impulsivity (errors) @ 54 mo & $-0.04(0.04)$ & 0.37 & $-0.01(0.03)$ & 0.71 & $-0.01(0.03)$ & 0.73 & $-0.13^{*}(0.04)$ & 0.03 & $-0.11(0.03)$ & 0.05 & $-0.10(0.03)$ & 0.05 & $-0.01(0.04)$ & 0.72 & $0.01(0.03)$ & 0.83 & $0.02(0.03)$ & 0.67 & $7 \quad-0.03(0.03)$ & 0.42 & $-0.01(0.03)$ & 0.84 & $0.00(0.03)$ & 0.95 \\
\hline Applied Problems @ 54 mo & & & $0.15^{* \mathrm{k}}(0.05)$ & 0.04 & $0.1(0.05)$ & 0.11 & & & $6^{* * * * \text { thb }}(0.04)$ & 0.000 & $0.32 * *$ hb $(0.04)$ & 0.00 & & & $0.28^{* * \mathrm{hb}}(0.05)$ & 0.000 . & $0.23^{* * k^{\mathrm{hb}}}(0.05)$ & 0.01 & & & 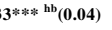 & $0.00 \mathrm{o}$ & $.31 * * *$ hb $(0.05)$ & 0.00 \\
\hline Picture Vocabulary @54 mo & & & $0.50^{* * * \text { kh }}(0.04)$ & 0.00 & $0.39^{* * * \text { hb }}(0.04)$ & 0.00 & & & $.22^{* * \text { hb }}(0.04)$ & 0.00 & $0.14^{*}(0.04)$ & 0.03 & & & $0.26^{* * * * \mathrm{hb}_{0}}(0.04)$ & 0.000. & $0.20^{* * \text { hb }}(0.04)$ & 0.01 & & & $.2^{2 * * \text { *h }}(0.04)$ & 0.01 & $0.10(0.04)$ & 0.06 \\
\hline Child's Ethnicity: Black & & & & & $-0.16^{* * h}(0.04)$ & 0.01 & & & & & $-0.11(0.05)$ & 0.07 & & & & & $-0.08(0.04)$ & 0.12 & & & & & $-0.06(0.04)$ & 0.20 \\
\hline Male child & & & & & $0.10^{*^{\mathrm{h}}}(0.03)$ & 0.01 & & & & & $0.05(0.03)$ & 0.23 & & & & & $-0.01(0.03)$ & 0.82 & & & & & $0.15^{* * \mathrm{k}}(0.03)$ & 0.01 \\
\hline Ever in child care & & & & & $-0.05(0.03)$ & 0.17 & & & & & $-0.08(0.04)$ & 0.11 & & & & & $-0.08(0.04)$ & 0.12 & & & & & $-0.06(0.04)$ & 0.19 \\
\hline Maternal Education @birth & & & & & $0.18^{* * \text { hb }}(0.03)$ & 0.00 & & & & & $0.17^{* * \mathrm{hb}}(0.03)$ & 0.01 & & & & & $0.16^{* * \mathrm{~kb} b}(0.03)$ & 0.01 & & & & & $0.17 * *$ hb $(0.03)$ & 0.01 \\
\hline Avg Household Income 1-54months & & & & & $-0.03(0.04)$ & 0.42 & & & & & $-0.02(0.04)$ & 0.57 & & & & & $-0.03(0.03)$ & 0.41 & & & & & $0.00(0.03)$ & 0.94 \\
\hline Total Household Size @ @4 mo & & & & & $-0.06(0.03)$ & 0.07 & & & & & $-0.04(0.03)$ & 0.20 & & & & & $-0.01(0.03)$ & 0.66 & & & & & $-0.05(0.03)$ & 0.16 \\
\hline Child age in months & & & & & $-0.04(0.03)$ & 0.19 & & & & & $-0.01(0.02)$ & 0.69 & & & & & $-0.05(0.03)$ & 0.18 & & & & & $-0.02(0.03)$ & 0.49 \\
\hline Total HOME score @ 54 mo & & & & & $0.06(0.04)$ & 0.18 & & & & & $0.05(0.04)$ & 0.27 & & & & & $0.09(0.04)$ & 0.07 & & & & & $0.05(0.03)$ & 0.18 \\
\hline Constant & $0.00(0.05)$ & 1.00 & $0.00(0.03)$ & 0.99 & $0.00(0.03)$ & 0.99 & $0.00(0.05)$ & 1.00 & $0.00(0.03)$ & 1.00 & $0.00(0.03)$ & 1.00 & $0.00(0.06)$ & 1.00 & $0.00(0.05)$ & 1.00 & $0.00(0.04)$ & 1.00 & $-0.27^{\text {thb }}(0.10)$ & 0.04 & $0.00(0.04)$ & 1.00 & $0.00(0.04)$ & 1.00 \\
\hline $\begin{array}{l}\text { Adjusted R-Squared Range } \\
\end{array}$ & 0.140 .19 & & $0.37-0.42$ & & 0.440 .50 & & $0.17-0.22$ & & $0.33-0.39$ & & $0.38-0.43$ & & $0.19-0.26$ & & $0.32-0.39$ & & $0.38-0.44$ & & $0.16-0.20$ & & $0.30-0.34$ & & $0.36-0.40$ & \\
\hline
\end{tabular}




\section{Appendix A.}

Unimputed Correlations for Study Variables

\begin{tabular}{|c|c|c|c|c|c|c|c|c|c|c|c|c|c|c|c|c|c|c|c|c|c|c|}
\hline & 1 & 2 & 3 & 4 & 5 & 6 & 7 & 8 & 9 & 10 & 11 & 12 & 13 & 14 & 15 & 16 & 17 & 18 & 19 & 20 & 21 & 22 \\
\hline 1. Planning at age 15 & 1 & & & & & & & & & & & & & & & & & & & & & \\
\hline 2. Working Memory at age 15 & 0.16 & 1 & & & & & & & & & & & & & & & & & & & & \\
\hline 3. Inhibition at age 15 & 0.00 & 0.08 & 1 & & & & & & & & & & & & & & & & & & & \\
\hline 4. Picture Vocabulary at age 15 & 0.17 & 0.29 & 0.02 & 1 & & & & & & & & & & & & & & & & & & \\
\hline 5. Verbal Analogies at age 15 & 0.20 & 0.34 & 0.04 & 0.64 & 1 & & & & & & & & & & & & & & & & & \\
\hline 6. Passage Comprehension at age 15 & 0.20 & 0.36 & 0.06 & 0.71 & 0.70 & 1 & & & & & & & & & & & & & & & & \\
\hline 7. Applied Problems at age 15 & 0.25 & 0.36 & 0.04 & 0.61 & 0.69 & 0.69 & 1 & & & & & & & & & & & & & & & \\
\hline 8. Delay of Gratification @ 54 mo & 0.10 & 0.14 & 0.03 & 0.26 & 0.28 & 0.31 & 0.28 & 1 & & & & & & & & & & & & & & \\
\hline 9. Working Memory @54 mo & 0.11 & $\mathbf{0 . 3 3}$ & 0.07 & 0.37 & 0.37 & 0.42 & 0.35 & 0.29 & 1 & & & & & & & & & & & & & \\
\hline 10. Sustained Attention @ 54 mo & -0.04 & -0.19 & -0.07 & -0.17 & -0.23 & -0.21 & -0.21 & -0.25 & -0.24 & 1 & & & & & & & & & & & & \\
\hline 11. Inhibition@54 mo & -0.04 & -0.12 & -0.02 & -0.09 & -0.18 & -0.08 & -0.09 & -0.10 & -0.08 & 0.09 & 1 & & & & & & & & & & & \\
\hline 12. Applied Problems @ 54 mo & 0.11 & 0.32 & 0.05 & 0.45 & 0.54 & 0.51 & 0.49 & 0.37 & 0.49 & -0.36 & -0.11 & 1 & & & & & & & & & & \\
\hline 13. Picture Vocabulary @54 mo & 0.10 & 0.22 & -0.04 & 0.61 & 0.46 & 0.51 & 0.43 & 0.28 & 0.46 & -0.24 & -0.08 & 0.54 & 1 & & & & & & & & & \\
\hline 14. Child's Ethnicity: Black & -0.01 & -0.14 & 0.02 & -0.41 & -0.36 & -0.35 & -0.31 & -0.27 & -0.18 & 0.14 & 0.01 & -0.34 & -0.36 & 1 & & & & & & & & \\
\hline 15. Male child & 0.02 & -0.01 & -0.12 & 0.10 & -0.01 & -0.04 & 0.09 & -0.07 & -0.07 & 0.06 & 0.06 & -0.14 & 0.06 & -0.01 & 1 & & & & & & & \\
\hline 16. Ever in child care & 0.04 & 0.03 & -0.01 & 0.11 & 0.08 & 0.09 & 0.10 & 0.14 & 0.15 & -0.09 & -0.05 & 0.15 & 0.15 & -0.05 & -0.02 & 1 & & & & & & \\
\hline 17. MaternalEducation@birth & 0.11 & 0.18 & 0.02 & 0.44 & 0.42 & 0.42 & 0.41 & 0.28 & 0.29 & -0.19 & -0.11 & 0.38 & 0.40 & -0.26 & -0.03 & 0.27 & 1 & & & & & \\
\hline 18. Avg Household Income 1-54months & $\mathbf{0 . 1 0}$ & 0.09 & 0.00 & 0.31 & $\mathbf{0 . 3 0}$ & $\mathbf{0 . 3 0}$ & 0.30 & 0.25 & 0.25 & -0.12 & -0.10 & 0.32 & 0.35 & -0.29 & -0.06 & 0.25 & 0.59 & 1 & & & & \\
\hline 19. Total Household Size @ 54 mo & -0.04 & -0.04 & -0.06 & -0.13 & -0.10 & -0.09 & -0.11 & -0.08 & -0.13 & 0.08 & 0.05 & -0.08 & -0.14 & 0.04 & -0.01 & -0.10 & -0.08 & -0.13 & 1 & & & \\
\hline 20. Child age in months & -0.02 & -0.03 & 0.01 & -0.07 & -0.03 & -0.06 & -0.03 & -0.04 & -0.01 & -0.06 & -0.04 & 0.02 & 0.00 & 0.02 & -0.04 & 0.01 & -0.02 & -0.01 & 0.03 & 1 & & \\
\hline 21. HOME @3rd grade: learning materials & $\mathbf{0 . 0 7}$ & 0.19 & 0.06 & 0.42 & 0.41 & 0.43 & 0.39 & 0.31 & 0.36 & -0.23 & -0.11 & 0.43 & 0.42 & -0.39 & -0.08 & 0.13 & 0.52 & 0.41 & -0.17 & 0.06 & 1 & \\
\hline 22. Site & 0.01 & -0.03 & -0.04 & 0.06 & 0.04 & 0.08 & 0.04 & 0.01 & 0.07 & 0.06 & 0.05 & 0.02 & 0.06 & -0.06 & -0.03 & -0.05 & -0.01 & -0.05 & -0.08 & -0.09 & 0.14 & 1 \\
\hline
\end{tabular}

Note. Bolded correlations are significant at $p<.05$ 
Table 2A. Hierarchical Regression Models Predicting Executive Functioning at Age 15 with 25 Imputed Data Sets (N=1273)

\begin{tabular}{|c|c|c|c|c|c|c|c|c|c|c|c|c|c|c|c|c|c|c|}
\hline & \multicolumn{6}{|c|}{ Planning at age 15} & \multicolumn{6}{|c|}{ Working Memory at age 15} & \multicolumn{6}{|c|}{ Inhibition at age 15} \\
\hline & \multicolumn{2}{|c|}{ Model 1} & \multicolumn{2}{|c|}{ Model 2} & \multicolumn{2}{|c|}{ Model 3} & \multicolumn{2}{|l|}{ Model 1} & \multicolumn{2}{|c|}{ Model 2} & \multicolumn{2}{|l|}{ Model 3} & \multicolumn{2}{|l|}{ Model 1} & \multicolumn{2}{|c|}{ Model 2} & \multicolumn{2}{|l|}{ Model 3} \\
\hline & $\mathrm{b}(\mathrm{SE})$ & $\mathrm{p}$ & $\mathrm{b}(\mathrm{SE})$ & $\mathrm{p}$ & $\mathrm{b}(\mathrm{SE})$ & $p$ & $\mathrm{~b}(\mathrm{SE})$ & $\mathrm{p}$ & $\mathrm{b}(\mathrm{SE})$ & $\mathrm{p}$ & $\mathrm{b}(\mathrm{SE})$ & $\mathrm{p}$ & $\mathrm{b}(\mathrm{SE})$ & $\mathrm{p}$ & $\mathrm{b}(\mathrm{SE})$ & $\mathrm{p}$ & $\mathrm{b}(\mathrm{SE})$ & $\mathrm{p}$ \\
\hline Delay of Gratification @ 54 mo & $0.07(0.04)$ & 0.128 & $0.06(0.04)$ & 0.252 & $0.06(0.04)$ & 0.258 & $0.02(0.04)$ & 0.643 & $-0.02(0.05)$ & 0.722 & $-0.02(0.05)$ & 0.692 & $0.00(0.04)$ & 0.945 & $0.01(0.04)$ & 0.784 & $0.01(0.04)$ & 0.750 \\
\hline Working Memory @54 mo & $0.08(0.04)$ & 0.089 & $0.04(0.04)$ & 0.358 & $0.03(0.04)$ & $0.468 \mathbf{0 . 2 8}$ & $* * * \mathrm{hb}(0.05)$ & 0.001 & $0.21 * *$ hb $(0.05)$ & 0.006 & $0.21 * *$ hb $(0.05)$ & 0.006 & $0.05(0.04)$ & 0.269 & $0.08(0.05)$ & 0.111 & $0.07(0.04)$ & 0.162 \\
\hline Sustained Attention @ 54 mo & $-0.02(0.03)$ & 0.678 & $0.00(0.03)$ & 0.946 & $0.00(0.03)$ & 0.895 & $-0.10(0.04)$ & 0.055 & $-0.06(0.04)$ & 0.209 & $-0.06(0.04)$ & 0.212 & $-0.05(0.04)$ & 0.31 & $-0.05(0.04)$ & 0.294 & $-0.05(0.04)$ & 0.332 \\
\hline Impulsivity (errors) @54 mo & $-0.03(0.04)$ & 0.532 & $-0.03(0.04)$ & 0.582 & $-0.02(0.04)$ & 0.670 & $-0.07(0.04)$ & 0.163 & $-0.06(0.04)$ & 0.208 & $-0.07(0.04)$ & 0.175 & $-0.02(0.04)$ & 0.648 & $-0.02(0.04)$ & 0.621 & $-0.01(0.04)$ & 0.759 \\
\hline Applied Problems @54 mo & & & $0.06(0.06)$ & 0.418 & $0.07(0.06)$ & 0.335 & & & $0.19 *^{* \mathrm{~h}}(0.05)$ & 0.012 & $0.18^{* \mathrm{~h}}(0.05)$ & 0.017 & & & $0.05(0.05)$ & 0.421 & $0.04(0.06)$ & 0.543 \\
\hline Picture Vocabulary @54 mo & & & $0.04(0.04)^{\prime}$ & 0.370 & $0.04(0.05)$ & 0.507 & & & $0.00(0.04)$ & 0.956 & $-0.01(0.04)$ & 0.845 & & & $-0.13(0.05)$ & 0.051 & $-0.11(0.05)$ & 0.093 \\
\hline Child's Ethnicity: Black & & & & & $0.07(0.05)$ & 0.218 & & & & & $-0.03(0.05)$ & 0.604 & & & & & $0.04(0.04)$ & 0.441 \\
\hline Male child & & & & & $0.03(0.04)$ & 0.443 & & & & & $0.02(0.03)$ & 0.581 & & & & & $-0.09(0.04)$ & 0.062 \\
\hline Ever in child care & & & & & $-0.03(0.05)$ & 0.602 & & & & & $-0.05(0.04)$ & 0.334 & & & & & $-0.05(0.04)$ & 0.346 \\
\hline Maternal Education @ birth & & & & & $0.04(0.05)$ & 0.405 & & & & & $0.07(0.04)$ & 0.185 & & & & & $0.01(0.04)$ & 0.764 \\
\hline Avg Household Income 1-54months & & & & & $0.02(0.04)$ & 0.580 & & & & & $-0.06(0.05)$ & 0.242 & & & & & $-0.02(0.04)$ & 0.713 \\
\hline Total Household Size @ 54 mo & & & & & $-0.03(0.04)$ & 0.476 & & & & & $0.00(0.04)$ & 0.921 & & & & & $-0.05(0.03)$ & 0.143 \\
\hline Child age in months & & & & & $-0.02(0.03)$ & 0.619 & & & & & $-0.04(0.03)$ & 0.319 & & & & & $0.00(0.04)$ & 0.990 \\
\hline Total HOME score @54 mo & & & & & $0.01(0.05)$ & 0.901 & & & & & $0.01(0.04)$ & 0.838 & & & & & $0.03(0.05)$ & 0.605 \\
\hline Constant & $0.00(0.04)$ & 0.998 & $0.00(0.04)$ & 0.998 & $0.00(0.04)$ & 0.998 & $0.00(0.03)$ & 0.993 & $0.00(0.03)$ & 0.991 & $0.00(0.03)$ & 0.987 & $0.00(0.05)$ & 0.997 & $0.00(0.05)$ & 0.996 & $0.00(0.05)$ & 0.992 \\
\hline Adjusted R-Squared Range & $0.01-0.03$ & & $0.02-0.05$ & & $0.03-0.05$ & & $0.10-0.15$ & & $0.12-0.17$ & & $0.13-0.19$ & & $0.00-0.01$ & & $0.01-0.03$ & & $0.03-0.05$ & \\
\hline
\end{tabular}

Note: All variables are z-scores. All steps clustered by site. H indicates significant after Holms correction. B indicates significant after Bonferroni correction ( $\mathrm{p} \leq 0.007)$. 
Table 3A. Hierarchical Regression Models Predicting Achievement at Age 15 with 25 Imputed Data Sets (N=1273)

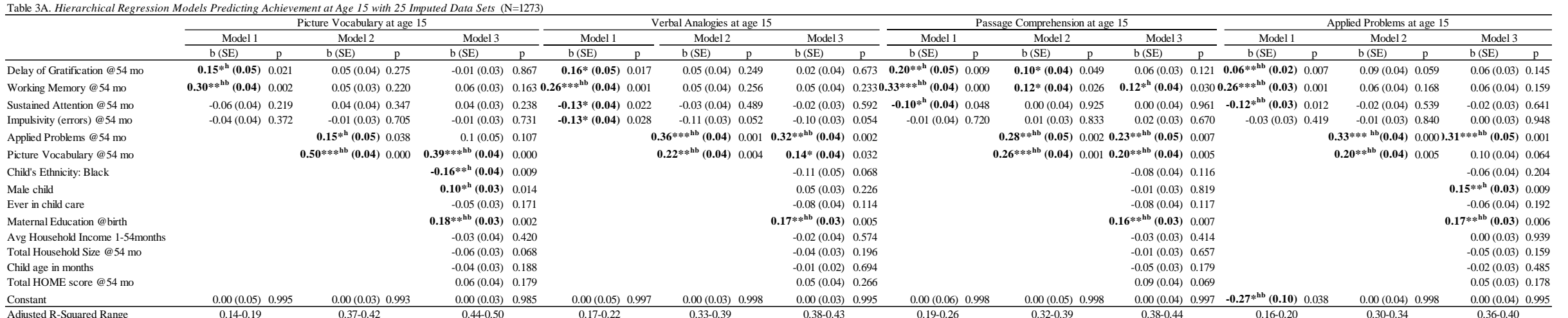

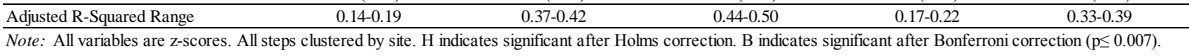

